\title{
Repeated colonoscopy results after an unsuccessful procedure due to inadequate bowel cleansing
}

\author{
Murat Yıldırım,' (1) Uğur Özsoy, ${ }^{1}$ (1) Celil Uğurlu, ${ }^{1}$ (1) Bülent Koca, ${ }^{1}$ (1) Abdullah Özgür Yeniova, ${ }^{2}$ \\ İsmail Okan' \\ 'Departman of General Surgery, Gaziosmapaşa University, Tokat, Turkey \\ ${ }^{2}$ Department of Internal Medicine Division of Gastroenterology, Gaziosmapaşa University, Tokat, Turkey
}

\begin{abstract}
Introduction: The aim of this study is to evaluate repeated colonoscopy results after a failed procedure due to inadequate bowel cleansing.

Materials and Methods: Patients who underwent colonoscopy between the dates of January 2014 and December 2019 were included in the study. Patients' distance from the hospital, appointment times, repeated colonoscopy times, demographic data, and predictive factors were evaluated.

Results: There were $522(5.1 \%)$ patients who had failed procedure due to insufficient bowel cleansing among the 10,420 colonoscopy procedures. Failure rates were increased in each repeated colonoscopies $(21.8 \%$, $25 \%$, and $33.3 \%$ ). In repeated second colonoscopy, if the procedure was on the same day and the next day, it was associated with a high success rate (odds ratio $[\mathrm{OR}]=3.31,95 \%$ confidence interval $[\mathrm{CI}]=0.91-12.36$; $\mathrm{p}=0.048, \mathrm{OR}=3.22,95 \% \mathrm{Cl}=1.26-8.24 ; \mathrm{p}=0.011$, respectively). Elder age $(\mathrm{OR}=1.04,95 \% \mathrm{Cl}=1.02-1.06$; $p<0.001)$, diabetes mellitus ( $O R=5.23,95 \% \mathrm{Cl}=2.92-9.38 ; \mathrm{p}<0.001)$, neurologic disorders $(\mathrm{OR}=7.02,95 \%$ $\mathrm{Cl}=3.12-15.8 ; p<0.001)$, and constipation $(\mathrm{p}<0.001)$ were defined as risk factors for inadequate bowel cleansing. Patients who did not attend the second recurrent colonoscopy appointment had a significantly higher distance from the hospital compared to the patients who attended the appointment $(p<0.001)$.

Conclusion: The failure rates in repeated colonoscopies after inadequate bowel preparation continue exponentially. In this difficult patient group, failure rates can be reduced by repeating colonoscopy on the same day or the next day. It is extremely important to know the risk factors before the procedure and to determine patient management accordingly.

Keywords: Colonoscopy, inadequate bowel preparation, repeat colonoscopy
\end{abstract}

\section{Introduction}

Colonoscopy is a unique endoscopic procedure that is widely used in the diagnosis of colon diseases and accepted as the gold standard for imaging the colon. ${ }^{[1]}$ In the colonoscopy procedure, adequate colon cleansing should be provided to visualize and evaluate the entire mucosa. Insufficient bowel preparation causes overlooked pathological lesions, repetition of the procedure, loss of labor and time, cost increase, and decreased patient satisfaction. ${ }^{[2,3]}$ However, inadequate bowel cleansing is reported 
in up to $25-30 \%$ of all colonoscopies. ${ }^{[4,5]}$ In the previous studies, the determinants of poor bowel preparation were shown as having a previous inadequate bowel preparation, long waiting time, advanced age, male gender, and concomitant diseases. ${ }^{[6-8]}$

There is no consensus on the management of colonoscopy procedures that fail due to insufficient bowel cleansing. While the European Society of Gastrointestinal Endoscopy recommends repeating the procedure the next day if possible, American guidelines recommend trying the same-day recovery methods or canceling the procedure and repeating the procedure within 1 year. ${ }^{[9-11]}$

The aim of this study is to examine the results of repeated colonoscopies and management protocols in patients who had a failed first colonoscopy because of inadequate bowel cleansing. The secondary aim is to reveal the predictors of failures in repeated colonoscopies.

\section{Materials and Methods}

Colonoscopy procedures performed in the endoscopy unit of Gaziosmanpasa Universty University (GOP) Faculty of Medicine between the dates of January 2014 and December 2019 were retrospectively scanned. Ethical approval was obtained from the local ethics committee of GOP Faculty of Medicine (approval number: 20- KAEK188).

Our hospital is a tertiary reference hospital serving approximately 600.000 people and accepting referrals from nearby provinces with rural areas. Two-thirds of the central population lives in rural areas. The distance to the city center varies between 20 and 120 kilometers $(\mathrm{km})$, and patients usually reach the hospital with their own means. In our unit, colonoscopy is performed on an average of 2000 patients annually. Colonoscopy appointments are made during the outpatient clinic examination. The maximum appointment time is 180 days for outpatients and non-emergency patients in routine procedures. All endoscopies were performed by experienced general surgery specialists and gastroenterologists.

Patients who failed the procedure due to insufficient bowel cleansing after the first colonoscopy procedure were examined. The anamnesis, clinical data, and address information of the patients were examined and recorded from the hospital database. The distance of the patients from the residence information to the hospital was obtained from the hospital database and it was calculated in kilometers. Failed colonoscopy due to insufficient bowel cleansing was determined by the colonoscopy reports created by the endoscopist and colon segment images recorded in the image transfer system. Successful colonoscopy was determined by the endoscopy report and the images that the cecum/terminal ileum had been visualized. The time between the first, second, third, and fourth colonoscopies was investigated if there was a repeated colonoscopy. Repeated colonoscopies were performed by the endoscopists who performed the first colonoscopy. Successful colonoscopy reports of the patients were recorded in terms of pathologies (polyps and neoplasia).

Patients under 18 years of age, failed colonoscopies due to any reason other than insufficient bowel preparation (pain, hypoxia, hypertension, etc.) and emergency colonoscopy procedures were excluded from the study.

\section{Bowel Preparation and Colonoscopy Procedure}

The patients were informed both by written information and verbally by the endoscopy nurse about the preparation the bowel. The patients were instructed to start bowel preparation 24-48 h before the colonoscopy procedure. They were ordered to eat only liquid foods (strained soup, pulp-free fruit juices, etc.) and drink plenty of water (at least $3 \mathrm{~L} /$ day) $24 \mathrm{~h}$ before, provided that they do not take anything orally after 00:00 at night before the procedure. They were instructed to drink a laxative solution (Sennoside A + B calcium) containing $250 \mathrm{ml}$ of senna by mixing with water or fruit juice, one at the noon, and one in the evening of the day before the procedure. An additional laxative dose was taken with approximately $1.5 \mathrm{~L}$ of water for the patients who had the procedure in the morning in repeated procedures on the same day. In the procedures performed the next day, the same laxatives were repeated with plenty of water in the evening and in the morning, and the colonoscopy was performed the next morning. Before the colonoscopy procedure, intravenous vascular access was established, $2 \mathrm{~L} / \mathrm{min}$ oxygen was provided by nasal cannula, and the pulse rate and oxygen saturation were monitored using a mobile pulse oximeter. 2-3 mg midazolam and $50 \mathrm{mg}$ pethidine $\mathrm{HCl}$ administered intravenously for sedation. Moderate sedation has generally been successful. Additional doses were administered in case of necessity during the procedure. Colonoscopy procedures were performed with Olympus and Fujinon brand colonoscopy devices. 


\section{Statistical Analysis}

Statistical analysis of the data was performed with the SPSS (SPSS Inc., Chicago, IL, USA) package program. The normal distribution of the data was tested with the Shapiro-Wilk test. A comparison of continuous variables between the two independent groups was carried out with the Students' t-test for normally distributed data, and the Mann-Whitney U-test for non-normally distributed data. The proportion comparisons and relationship analyzes between categorical variables were performed by the Chisquare test or Fisher's exact test in accordance with the number of data in crosstab cells. The statistical significance level was accepted as $\mathrm{p}<0.05$. Univariate and Multivariate Binary Logistic Regression analysis was used to determine the factors affecting the success of adequate colon cleansing. According to the univariate model results, variables with $\mathrm{p}<0.01$ significance level were included in the multivariate model. Odds ratio (OR) and 95\% Confidence interval (CI) values were also calculated for each parameter found statistically significant in the multivariate logistic regression analysis.

\section{Results}

There were 10.420 patients who underwent the first colonoscopy within the established time interval. The patient flow chart is summarized in Figure 1. Colonoscopy was failed in 522 patients (5.1\%) due to insufficient bowel preparation. Of these patients, $300(57.5 \%)$ were male and $222(42.5 \%)$ were female. The mean age of the patients was $63.74 \pm 13.54$ years. The average distance of the patients to the hospital was $44.92 \pm 32.18 \mathrm{~km}$. The data of $432(82.7 \%)$ patients who had a failed first colonoscopy and came to the second appointment were available and these patients constituted our main study group. Data were not available for the other 90 patients (17.2\%), as they did not come to the second appointment or had the procedure performed in another center. Of the 432 patients who came to the second appointment, 248 (57.4\%) were male and $184(42.6 \%)$ were female. Of the other 90 patients, 52 $(57.8 \%)$ were male and 38 (42.2\%) were female. Age and gender distributions were statistically similar $(\mathrm{p}=0.948$ and $p=0.263$, respectively). The mean age of these $432 \mathrm{pa}$ tients was $64.07 \pm 13.23$, and the mean age of 90 patients was $62.17 \pm 14.90$ years. The average distance of 90 patients who did not attend $(58.52 \pm 32.70 \mathrm{~km})$ was significantly higher than the 432 patients that attended $(42.09 \pm 31.37$ $\mathrm{km})$ the second appointment $(\mathrm{p}<0.001)$.

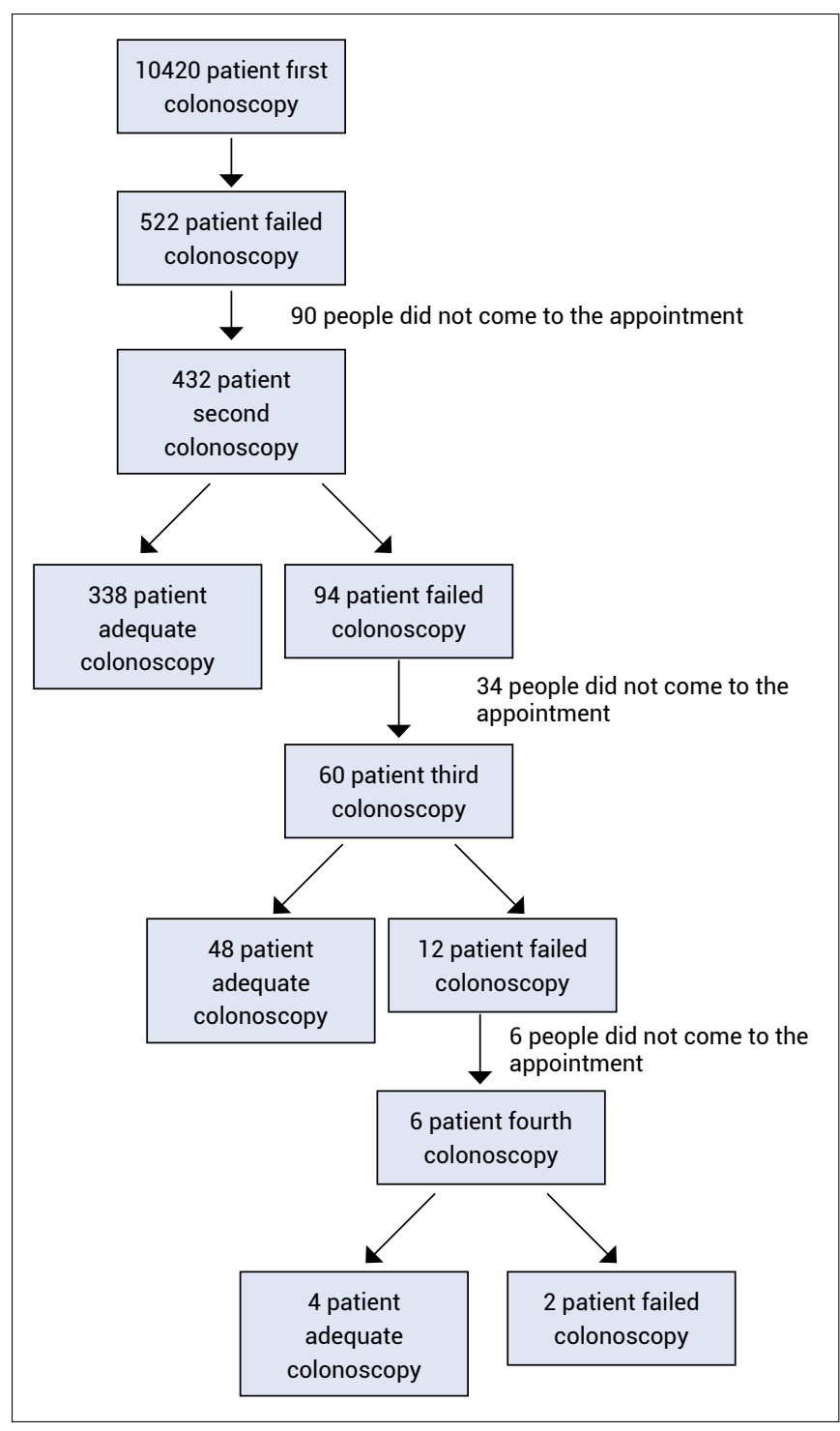

Figure 1. Colonoscopy patients flow chart.

$338(78.2 \%)$ of 432 patients who underwent the second colonoscopy had sufficient bowel cleansing and were named Group I. Colonoscopy was failed in 94 (21.8\%) patients due to insufficient bowel cleansing and they were classified as Group II. Demographic and patient clinical characteristics between these two groups are compared in Table 1. Age and comorbidity rates were statistically significantly higher in Group II ( $\mathrm{p}<0.001)$. In addition, the rates of diabetes mellitus and neurological diseases (cardiovascular disease) were significantly higher in Group II $(p<0.001)$. Constipation was found to be a risk factor in the failed second colonoscopy in patients who had constipation as a colonoscopy indication $(\mathrm{p}<0.001)$ (Table 1$)$.

The appointment (procedure) times for the second procedure and the distance of the patients to the hospital were compared between Group I and Group II (Table 2). 
Table 1. Comparison of socio-demographic characteristics, comorbidities, and indications between the groups

\begin{tabular}{|c|c|c|c|c|c|}
\hline & \multicolumn{2}{|c|}{ Group I $(n=338)$} & \multicolumn{2}{|c|}{ Group II (n=94) } & $\mathbf{p}$ \\
\hline Gender (F/M) (n) & \multicolumn{2}{|c|}{$144 / 194$} & \multicolumn{2}{|c|}{$40 / 54$} & $0.993^{b}$ \\
\hline Age (years) median (min-max) & \multicolumn{2}{|c|}{$64(18-91)$} & \multicolumn{2}{|c|}{$71(41-89)$} & $<0.001^{a}$ \\
\hline \multirow[t]{2}{*}{ Distance to the hospital $(\mathrm{km})$ median (min-max) } & \multicolumn{2}{|c|}{$40(5-160)$} & \multicolumn{2}{|c|}{$45(5-130)$} & $0.072^{\mathrm{a}}$ \\
\hline & $\mathbf{n}$ & $\%$ & $\mathbf{n}$ & $\%$ & \\
\hline Comorbidities & 205 & 60.7 & 82 & 87.2 & $<0.001^{\mathrm{b}}$ \\
\hline Diabetes Mellitus & 44 & 13.0 & 35 & 37.2 & $<0.001^{b}$ \\
\hline Neurological Disease & 14 & 4.1 & 19 & 20.2 & $<0.001^{b}$ \\
\hline $\mathrm{CHF}$ & 40 & 11.8 & 11 & 11.7 & $0.972^{\mathrm{b}}$ \\
\hline CRF & 18 & 5.3 & 7 & 7.4 & $0.436^{b}$ \\
\hline Dementia/Alzheimer's & 15 & 4.4 & 9 & 9.6 & $0.054^{\mathrm{b}}$ \\
\hline Hypertension & 54 & 16.0 & 19 & 20.2 & $0.332^{\mathrm{b}}$ \\
\hline Cirrhosis & 6 & 1.8 & 5 & 5.3 & $0.067^{c}$ \\
\hline Other & 37 & 10.9 & 9 & 9.6 & $0.703^{b}$ \\
\hline Unspecified & 14 & 4.1 & 4 & 4.3 & $1.000 \mathrm{c}$ \\
\hline \multicolumn{6}{|l|}{ Indications } \\
\hline Constipation & 80 & 23.7 & 43 & 45.7 & $<0.001^{b}$ \\
\hline Weight loss & 14 & 4.1 & 2 & 2.1 & $0.540 c$ \\
\hline Diarrhea & 32 & 9.5 & 4 & 4.3 & $0.106^{b}$ \\
\hline Polyp/Tumor Control & 35 & 10.4 & 11 & 11.7 & $0.708^{b}$ \\
\hline Anemia & 33 & 9.8 & 13 & 13.8 & $0.258^{b}$ \\
\hline Rectal Bleeding & 40 & 11.8 & 3 & 3.2 & $0.013^{b}$ \\
\hline Abdominal Pain/Dyspepsia & 68 & 20.1 & 13 & 13.8 & $0.167^{b}$ \\
\hline Other & 6 & 1.8 & 3 & 3.2 & $0.416^{c}$ \\
\hline Unspecified & 5 & 1.5 & 1 & 1.1 & $1.000^{c}$ \\
\hline
\end{tabular}

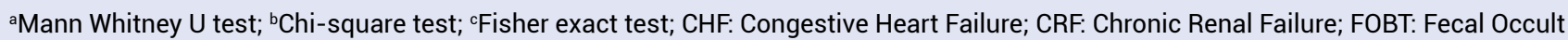
Blood Test; F: Female; M: Male; km: kilometers.

Table 2. Comparison between successful and failed groups in the second colonoscopy in terms of appointment time and distance to hospital

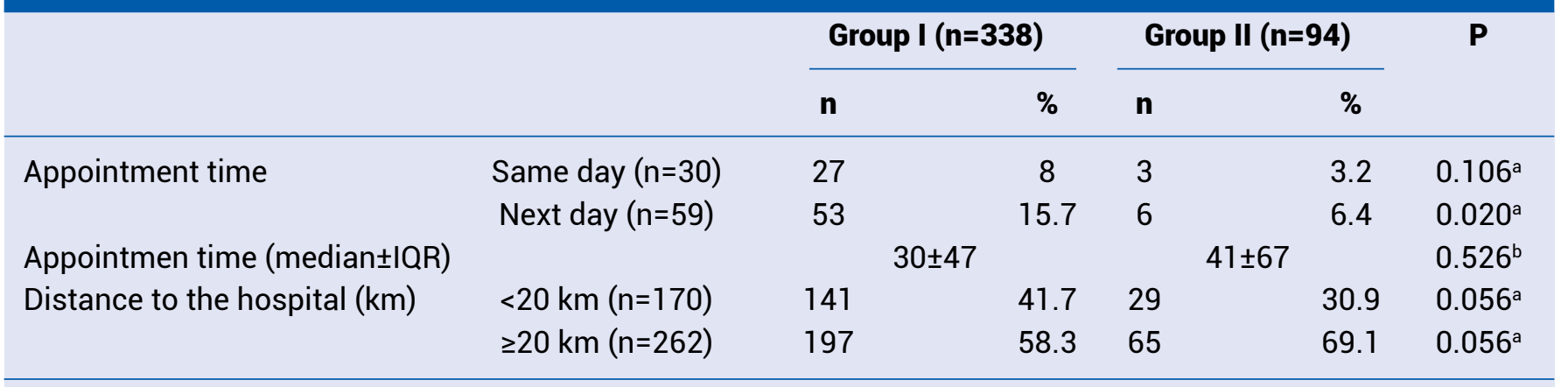

${ }^{a}$ Chi-square test; ${ }^{b}$ Mann Whitney $U$ test; IQR: Interquartile range.

Colonoscopy was repeated on the same day in 30 patients and the next day in 59 patients. Although the success rate was higher in procedures repeated on the same day, this rate was not statistically significant $(\mathrm{p}=0.106)$. In the colonoscopies repeated the next day, the success rate was statistically significantly higher $(\mathrm{p}=0.020$, Table 2$)$. 
The comparison of polyp and tumor detection rates between patients with adequate bowel cleansing in the second colonoscopy and patients with recurrent colonoscopy (third and fourth) is presented in Table 3. There was no statistically significant difference between the groups ( $p>0.05)$.

The results of univariate and multivariate binary logistic regression analysis performed to determine the factors and OR values on successful colonoscopy as a result of ad- equate bowel cleansing are given in Table 4. Gender and comorbidity variables (congestive heart failure, chronic renal failure, and hypertension) which were not found to be significant in the univariate model $(p>0.01)$ were not included in the multivariate model. Variables found to be significant in the univariate model but not significant in the multivariate model were also not included in the final model. According to the multivariate model results, if the age of the patient who applied was 1 unit younger it in-

Table 3. The comparison of polyp, tumor detection rates, and polyp size between patients with adequate bowel cleansing in the second colonoscopy and patients with recurrent colonoscopy (third and fourth)

\begin{tabular}{|c|c|c|c|c|c|}
\hline & \multicolumn{2}{|c|}{$\begin{array}{l}\text { Adequate colonoscopy } \\
\qquad \begin{array}{c}\text { (second) } \\
n=338\end{array}\end{array}$} & \multicolumn{2}{|c|}{$\begin{array}{l}\text { Third and fourth } \\
\text { adequate colonoscopy } \\
\qquad n=49\end{array}$} & \multirow[t]{2}{*}{$\mathbf{p}$} \\
\hline & $\mathbf{n}$ & $\%$ & $\mathbf{n}$ & $\%$ & \\
\hline Polyp & 60 & 17.8 & 9 & 18.4 & $0.916^{a}$ \\
\hline Tumor Mass & 7 & 2.1 & 1 & 2 & $1.000^{\mathrm{b}}$ \\
\hline \multicolumn{6}{|l|}{ Polyp Size } \\
\hline$<10 \mathrm{~mm}$ & 50 & 14.8 & 9 & 18.4 & $0.515^{a}$ \\
\hline$\geq 10 \mathrm{~mm}$ & 10 & 3 & 0 & 0 & $0.622^{b}$ \\
\hline
\end{tabular}

${ }^{\mathrm{a} C h i}$-square test; ${ }^{\mathrm{b}}$ Fisher exact test mm: milimeters.

Table 4. Univariate and multivariate logistic regression analysis results

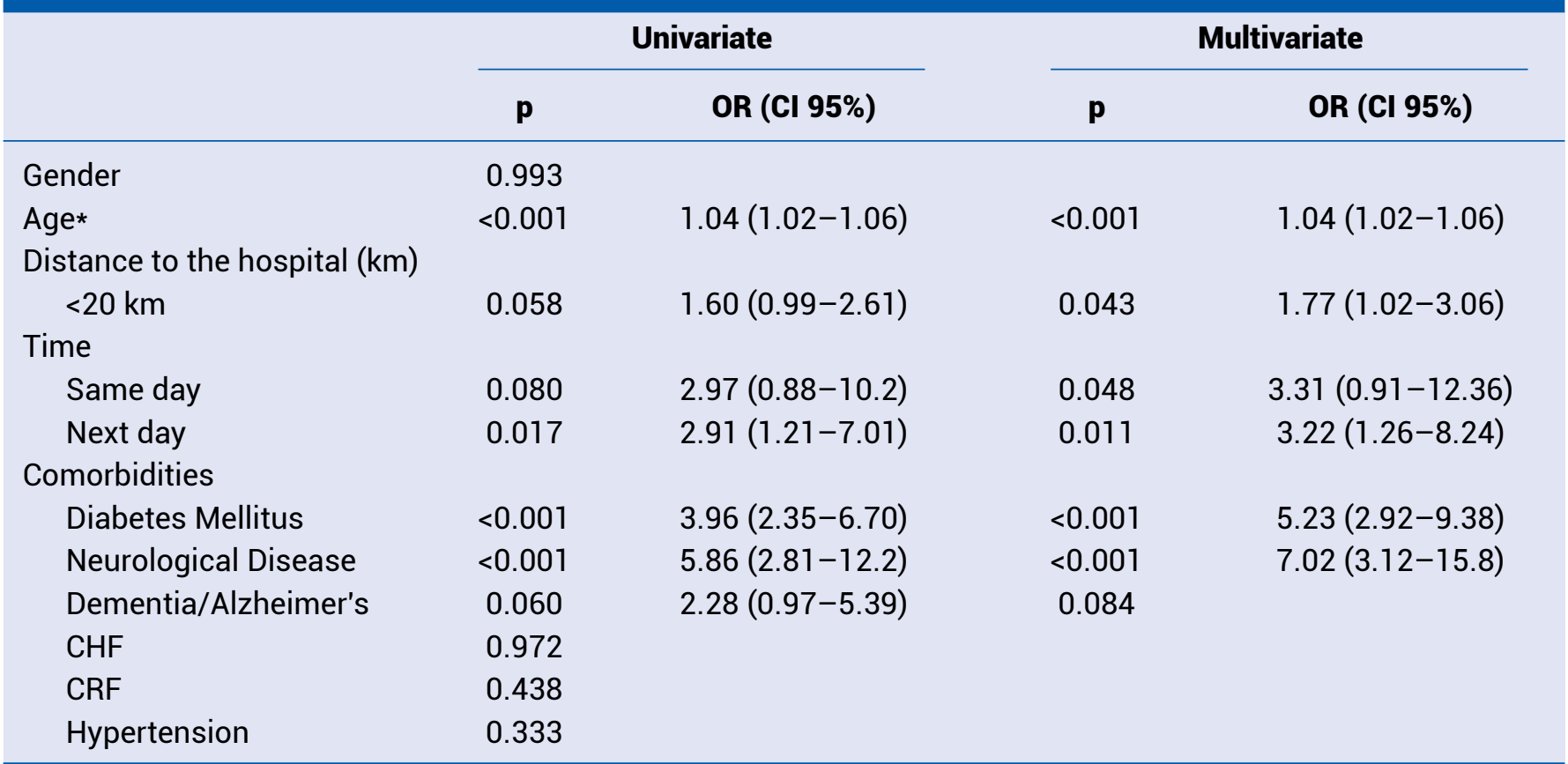

*Protective effect (Since OR $<1,1 /$ OR conversion was made); The reference value for additional disease: Presence; The reference value for distance to the hospital: >20 km; Reference value for time: >1 day; CHF: Congestive Heart Failure; CRF: Chronic Renal Failure; km: kilometers; OR: Odds ratio; Cl: Confidence interval. 
creased the success of 1.04 (1.02-1.06) times. Being closer than $20 \mathrm{~km}$ to the hospital increased the success by 1.77 (1.02-3.06) times compared to those far from $20 \mathrm{~km}$. The procedure applied on the same day increased the success by $3.31(0.91-12.36)$ times, and the procedure applied the next day increased the success by 3.22 (1.26-8.24) times. The success was increased by 5.23 (2.92-9.38) times in patients who had not a diagnosis of diabetes mellitus compared with the patients had. If the patients had not a diagnosis of neurological diseases, the success rate was increased 7.02 (3.12-15.8) times (Table 4).

Repeated colonoscopies after a failed second colonoscopy were also investigated. Consecutive colonoscopy results are shown in Figure 2. A third colonoscopy was performed for 60 of 94 patients who failed the second colonoscopy due to insufficient bowel cleansing. In 15 (25\%) of 60 patients, the procedure was failed again due to insufficient bowel cleansing. Nine of the 15 patients did not attend the recurring appointments and six patients had a fourth colonoscopy. It was observed that the procedure was unsuccessful in two (33.3\%) of six patients who underwent colonoscopy for the 4th time, again due to insufficient preparation quality. These two patients did not attend the fifth appointment.

\section{Discussion}

This study investigated the results of repeated colonoscopies which had been failed due to insufficient bowel cleansing. In addition, the risk factors for insufficient bowel preparation were characterized. While the failure rate in repeated second colonoscopy was $21 \%$, it was $25 \%$ and $33 \%$, respectively, in subsequent colonoscopies. These results showed that this group is a specific and difficult patient group compared to the patients who underwent colonoscopy in the general population. In addition, success rates of colonoscopies performed on the same

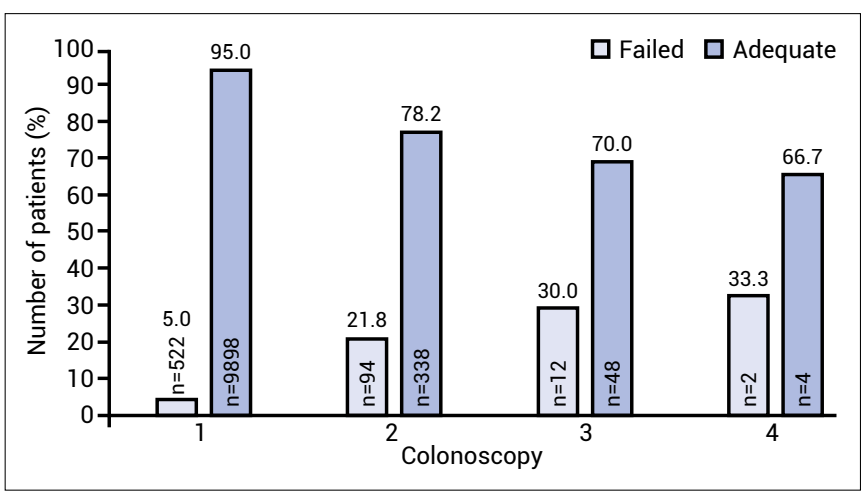

Figure 2. Results of the repeated colonoscopies. day and next day in repeated procedures were shown to be significant in multivariate analysis. Constipation, elder age, diabetes mellitus, and presence of neurological diseases have been shown to be risk factors for insufficient bowel preparation.

Failure due to poor bowel preparation - wastes extra time and cost for this patient group. This situation has encouraged institutions to frequently review and reconsider bowel preparation policies. In the current study, many parameters were examined to maximize the effectiveness of the preparation in repeated colonoscopy procedures and to determine risk factors. First of all, success rates of colonoscopies repeated on the same day, and the next day were found to be higher. Similar to this, in a prospective study, it was reported that it would be a safe and effective procedure if the colonoscopy that failed due to insufficient bowel cleansing was repeated in the afternoon with an additional laxative dose. ${ }^{[12]}$ In another retrospective study, patients who underwent repeated colonoscopy after insufficient cleaning were examined in two groups as the next day and the other days, but there was no difference between the two groups. ${ }^{[13]}$

A major problem with repeated colonoscopies was that patients did not come to the colonoscopy appointment. Approximately one-fourth of the patients did not come to the appointment in repeated procedures. Considering the rate of polyps and neoplasia detected in repetitive procedures in our study, this was seen as an important problem. Although our institution is a referral and tertiary reference hospital, as we have stated before, the majority of the patients living in rural areas. Therefore, we compared the distances to the hospital between the patients who attended and did not attend the second colonoscopy appointment. The distance from the hospital was statistically higher in the group who did not come. It is necessary to be careful when making appointments in this patient group and to plan the management well.

One of the aims of the study was to reveal risk factors for inadequate bowel cleansing. Elder age, constipation, diabetes mellitus, and the presence of neurological diseases were determined as predictors for poor bowel preparation. Inadequate bowel cleansing in elderly patients has been associated with causes such as comorbidities, difficulty in compliance with bowel cleansing, and polypharmacy. ${ }^{[14,15]}$ Consistent with findings from other studies constipation, neurological diseases, and diabetes mellitus were also significantly associated with inadequate bowel cleaning. ${ }^{[1,17]}$ 
As expected, inadequate bowel cleansing is shown to be an important risk factor in repeated colonoscopies. Similar to other studies, it was observed that the rate of detecting polyps, adenomas, and colorectal neoplasia increased significantly when the bowel preparation was adequate. ${ }^{[18,19]}$ In addition, it was shown that prolonging the appointment period negatively affects bowel cleansing. ${ }^{[8,20]}$ The appointment period was longer in the patient group who failed the second colonoscopy. The effect of increasing appointment time can be explained by the fact that patients forget bowel cleansing instructions and cause incorrect or incomplete use of medicines, especially in rural areas with low education levels.

There were some limitations of this study, one of which was its retrospective design. Possible factors such as medications used by patients and cleaning regimes could not be clearly evaluated. In addition, an internationally valid scoring system for bowel preparation was not used. However, this limitation is not specific to our study. There is no consensus even among experienced endoscopists in the evaluation of colon cleansing. ${ }^{[21,22]}$

As a result, the failure rate of repeated sequential colonoscopies continues to increase in the group of patients who failed due to insufficient bowel cleansing in the initial preparation. This rate can be reduced by colonoscopies performed on the same day or the next day. In addition, knowing the risk factors for insufficient cleaning and planning patient management accordingly is extremely important in terms of cost and hospital resources. Maximum attention should be paid to the planning of the patient group living in rural areas and far from the hospital.

\section{Ethical Standards}

All procedures followed were in accordance with the ethical standards of the responsible committee on human experimentation (institutional and national) and with the Declaration of Helsinki 1964 and later versions. Informed consent to be included in the study, or the equivalent, was obtained from all patients.

\section{Disclosures}

Ethichs Committee Approval: Ethical approval was obtained from the local ethics committee of Gaziosmanpasa Universty Faculty of Medicine (approval number: 20KAEK-188).

Peer-review: Externally peer-reviewed.
Conflict of Interest: None declared.

Authorship Contributions: Consept - M.Y., İ.O.; Desing - M.Y., U.O; Data collection and/or processing - M.Y., C.U., B.K.; Analysis and/or interpretation - M.Y., A.O.Y.; Writing - M.Y.; Critical review - İ.O.

\section{References}

1. Parmar R, Martel M, Rostom A, Barkun AN. Validated scales for colon cleansing: A systematic review. Am J Gastroenterol 2016;111:197-204; quiz 205. [CrossRef]

2. Froehlich F, Wietlisbach V, Gonvers JJ, Burnand B, Vader JP. Impact of colonic cleansing on quality and diagnostic yield of colonoscopy: The European panel of appropriateness of gastrointestinal endoscopy European multicenter study. Gastrointest Endosc 2005;61:378-84. [CrossRef]

3. Rex DK, Imperiale TF, Latinovich DR, Bratcher LL. Impact of bowel preparation on efficiency and cost of colonoscopy. Am J Gastroenterol 2002;97:1696-700. [CrossRef]

4. Alvarez-Gonzalez MA, Flores-Le Roux JA, Seoane A, PedroBotet J, Carot L, Fernandez-Clotet A, et al. Efficacy of a multifactorial strategy for bowel preparation in diabetic patients undergoing colonoscopy: A randomized trial. Endoscopy 2016;48:1003-9. [CrossRef]

5. Harewood GC, Sharma VK, de Garmo P. Impact of colonoscopy preparation quality on detection of suspected colonic neoplasia. Gastrointest Endosc 2003;58:76-9. [CrossRef]

6. Gimeno-García AZ, Baute JL, Hernandez G, Morales D, Gonzalez-Pérez CD, Nicolás-Pérez $D$, et al. Risk factors for inadequate bowel preparation: A validated predictive score. Endoscopy 2017;49:536-43. [CrossRef]

7. Borg BB, Gupta NK, Zuckerman GR, Banerjee B, Gyawali CP. Impact of obesity on bowel preparation for colonoscopy. Clin Gastroenterol Hepatol 2009;7:670-5. [CrossRef]

8. Chan WK, Saravanan A, Manikam J, Goh KL, Mahadeva S. Appointment waiting times and education level influence the quality of bowel preparation in adult patients undergoing colonoscopy. BMC Gastroenterol 2011;11:86. [CrossRef]

9. Hassan C, East J, Radaelli F, Spada C, Benamouzig R, Bisschops $\mathrm{R}$, et al. Bowel preparation for colonoscopy: European society of gastrointestinal endoscopy (ESGE) guideline update 2019. Endoscopy 2019;51:775-94. [CrossRef]

10. Lieberman DA, Rex DK, Winawer SJ, Giardiello FM, Johnson DA, Levin TR. Guidelines for colonoscopy surveillance after screening and polypectomy: A consensus update by the US multi-society task force on colorectal cancer. Gastroenterology 2012;143:844-57. [CrossRef]

11. Johnson DA, Barkun AN, Cohen LB, Dominitz JA, Kaltenbach $\mathrm{T}$, Martel $\mathrm{M}$, et al. Optimizing adequacy of bowel cleansing for colonoscopy: Recommendations from the US multi-society task force on colorectal cancer. Gastroenterology 2014;147:903-24. [CrossRef]

12. Akgul G, Ozgur Yeniova A, Ozsoy Z, Yenidogan E, Kefeli A, Dasıran MF, et al. Effect and tolerability of same-day repeat 
colonoscopy. J Invest Surg 2020;33:459-65. [CrossRef]

13. Murphy CJ, Jewel Samadder N, Cox K, Iqbal R, So B, Croxford $D$, et al. Outcomes of next-day versus non-next-day colonoscopy after an initial inadequate bowel preparation. Dig Dis Sci 2016;61:46-52. [CrossRef]

14. Heppner HJ, Christ M, Gosch M, Mühlberg W, Bahrmann P, Bertsch $\mathrm{T}$, et al. Polypharmacy in the elderly from the clinical toxicologist perspective. Z Gerontol Geriatr 2012;45:473-8.

15. Lebwohl B, Wang TC, Neugut Al. Socioeconomic and other predictors of colonoscopy preparation quality. Dig Dis Sci 2010;55:2014-20. [CrossRef]

16. Mahmood S, Farooqui SM, Madhoun MF. Predictors of inadequate bowel preparation for colonoscopy: A systematic review and meta-analysis. Eur J Gastroenterol Hepatol 2018;30:819-26. [CrossRef]

17. Hendry PO, Jenkins JT, Diament RH. The impact of poor bowel preparation on colonoscopy: A prospective single centre study of 10,571 colonoscopies. Colorectal Dis 2007;9:745-8.
18. Chokshi RV, Hovis CE, Hollander T, Early DS, Wang JS. Prevalence of missed adenomas in patients with inadequate bowel preparation on screening colonoscopy. Gastrointest Endosc 2012;75:1197-203. [CrossRef]

19. Lebwohl B, Kastrinos F, Glick M, Rosenbaum AJ, Wang T, Neugut Al. The impact of suboptimal bowel preparation on adenoma miss rates and the factors associated with early repeat colonoscopy. Gastrointest Endosc 2011;73:1207-14.

20. Lee J, Kim TO, Seo JW, Choi JH, Heo NY, Park J, et al. Shorter waiting times from education to colonoscopy can improve the quality of bowel preparation: A randomized controlled trial. Turk J Gastroenterol 2018;29:75-81. [CrossRef]

21. Ben-Horin S, Bar-Meir S, Avidan B. The impact of colon cleanliness assessment on endoscopists' recommendations for follow-up colonoscopy. Am J Gastroenterol 2007;102:26805. [CrossRef]

22. Larsen M, Hills $\mathrm{N}$, Terdiman J. The impact of the quality of colon preparation on follow-up colonoscopy recommendations. Am J Gastroenterol 2011;106:2058-62. [CrossRef] 